\title{
A Histological Study on the Nature of Human Interglobular Dentin
}

\author{
By \\ SUSUmu NAGAHAMA \\ Department of Anatomy, Nippon dental University, 1-9-20, \\ Fujimi, Chiyoda-ku, Tokyo 102, Japan \\ -Received for Publication, September 8, 1981-
}

Key words; Interglobular dentin, Dentinal fiber, Human teeth.

Summary: Using the modified Bielschowsky-Nagahama staining techniqe, I have hither to shown the enamel spindles, enamel lamellae, enamel tufts and the granular layers consiat of nothing else than the extention fibers, and here report new finding on the nature of interglobular dentin, When stained heavily with silver nitrate, interglobular dntin appears black, and around it there can be seen many fine fibers, these fine fibers are of course branches of dentinal fibers, and can be so by appropriate staining. From this it appears that the interglobular dentin consists of a mass of fine branches of dentinal fibers, and among the fine branches can be seen also some main dentinal fibers.

The opinion most investigators in relation to interglobular dentin is that calcification of dentin begins in the globular portion and homogeneous calcified dentin is formed as result of fusion under normal circumstances. If fusion did not take place at this site, an uncalcified portion would remain between the globules. This called interglobular dentin. Dentin tubules pass through the uncalcified areas. In the process of growth and development of dentin, rig-like and linear structures of calcification appear. The interglobular dentin remain uncalcified with sharp margins at the sites were globular structure is found continuously. In this study, the content of an interglobular dentin was studied histologically.

\section{Materials and Methods}

Human teeth were used as the material. The Bielschowsky staining method, modified by Nagahama ${ }^{1-4)}$ was employed and the details are not described here.

\section{Observations}

Interglobular dentin is filled with fine fibers, which are a collection of dentinal fibers (Fig. 1-4). Dentinal fibers, even the proximal ones, give out branches entering interglobular dentin. Some dentinal fibers pass through interglobular dentin and become fine fibers after branching out, filling the interglobular dentin (Fig. 5-8).

Each interglobular dentin communicates to neighboring ones with several fibers. Dentin fibers close to the interglobular 
dentin are found to be relted to this (Fig. $9-12)$.

\section{Results and Discussion}

The interglobular dentin of the human tooth is the site of incomplete calcification according to a generally unified view of investigators to date, and ultrastructural studies of its etiology have met with only limited success.

Calcoglobules formed during dentin development have been observed to appear at each junction, and that area of dentin that undergoes no further progress in calcification is believed to be left as interglobular dentin.

In the present study, staining by the Nagahama method, a modification of the Bielschowsky method, has revealed collections of fine fibers that fill the interglobular dentin.

The connection of these fine fibers with dentinal fibers has identified them as branches of dentinal fibers.

To date, dentinal fibers were believed to pass through interglobular dentin, but this appears to be erroneous. Ahrough some do pass through, others do not, and these fine branches have been found to enter the interglobular dentin with contributing branches from neighboring dentinal fibers.

One of the possible inducing causes for such an observed may be that branches of dentinal fibers may enter any uncalcified site to form groups, thus preventing the site from completely calcifying. The incompletely calcified site is them left to from interglobular dentin.

The following conclusions may be drawn from these findings. The content of interglobular dentin is filled with fine fibers that rcpresent branches from the dentinal fibers. Fibers passing through the interglobular dentin or neighboring dentinal fibers may also contribute. Each area of interglobular dentin is connected by the extension of these fibers.

\section{References}

1) Nagahama, S., Minami, E., Okada, Y., Sato, S., Otsuka, S. and Iibuchi, Y.: The Nature of Enamel Spindles in Human Teeth, Shigaku, 66: 630-639, 1979. (in Japanese)

2) Nagahama, S.: The Fine Structure of Human Lamellae and Tufts, Shigaku, 67: 325-333, 1979. (in Japanese)

3) Nagahama, S.: A Histological Study of the Nature and Structure of the Granular Layer in Human Dentine, Shigaku, 67: 428-438, 1979. (in Japanese)

4) Naghama, S., Editor: Atlas of Human Orlal Histology, V., 2: 31-23, 81-87, Ishiyaku Co., Tokyo Japan, 1957.

5) Fujita, T.: Histology of Tooth, V., I, Ishiyaku Co., Tokyo Japan, 1957.

6) Rhaskar, S. N.: Orban's histology and embryology, *Ed., 107-110, C. V. Mosby Co., Saint Louis, 1976. 


\section{PLATES}




\section{Explanation of Figures}

\section{Plate I}

Figs. 1, 2. The form of the intergloblar dentin. Nagahamas Silver stain. $\times 400$.

Figs. 3, 4. Dentail of the interglobular dentin, it can be seen the small fibers in to the interglobular dentin. Nagahama's Silver stain. $\times 1650$.

Figs. 5, 6. The small fibers in to the interglobular dentin is dentin fibers branched. Naganama's Silver stain. $\times 1650$. 
Plate I
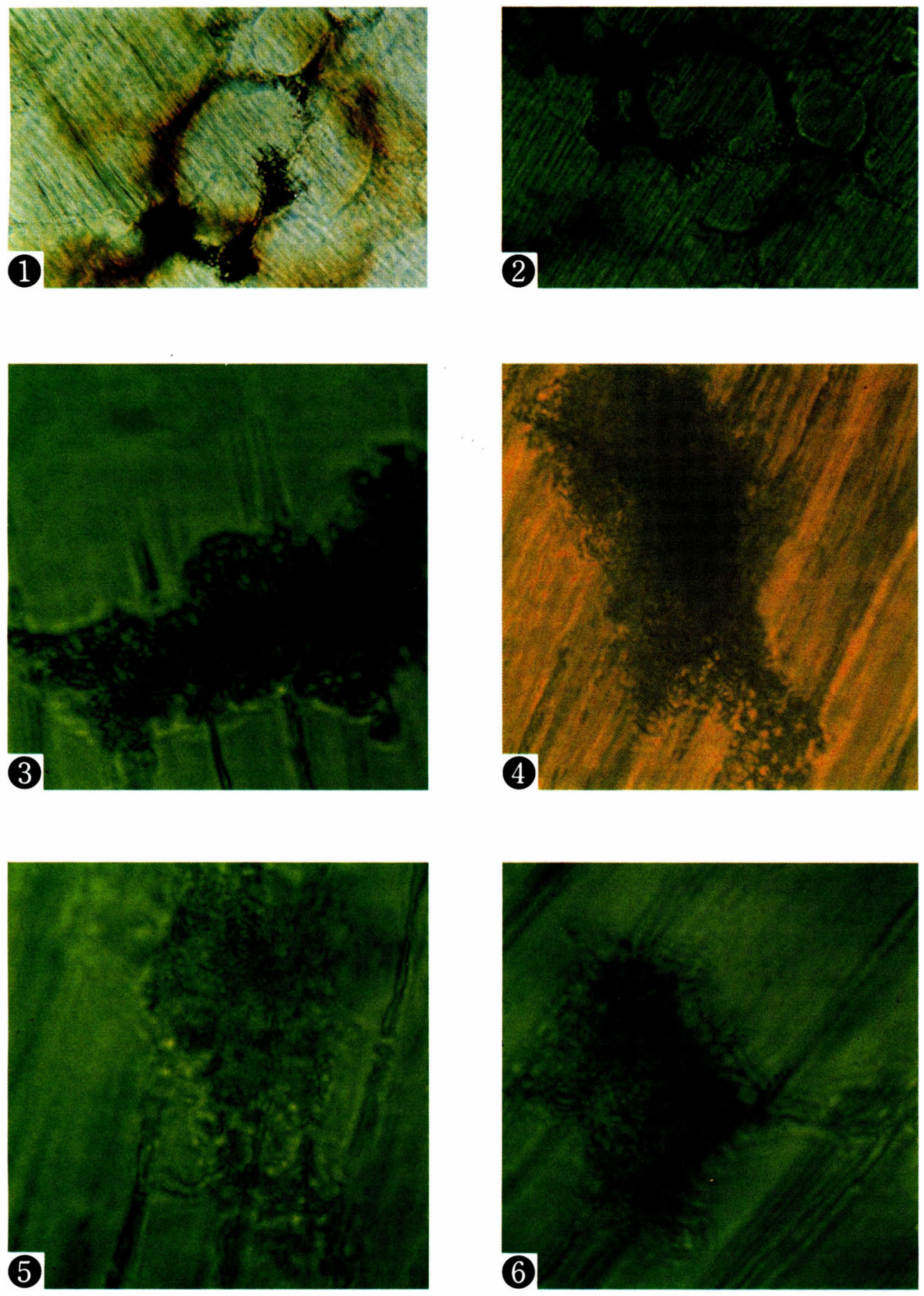

S. Nagahama 


\section{Plate II}

Figs. 7, 8. The small fibers in to the interglobular dentin is dentin fibers branched. Nagahama's Silver stain. $\times 1650$.

Figs. 9-12. The each interglobular dentin is continue by small fibers. Nagahama's Silver stain. $\times 1650$. 
Plate II
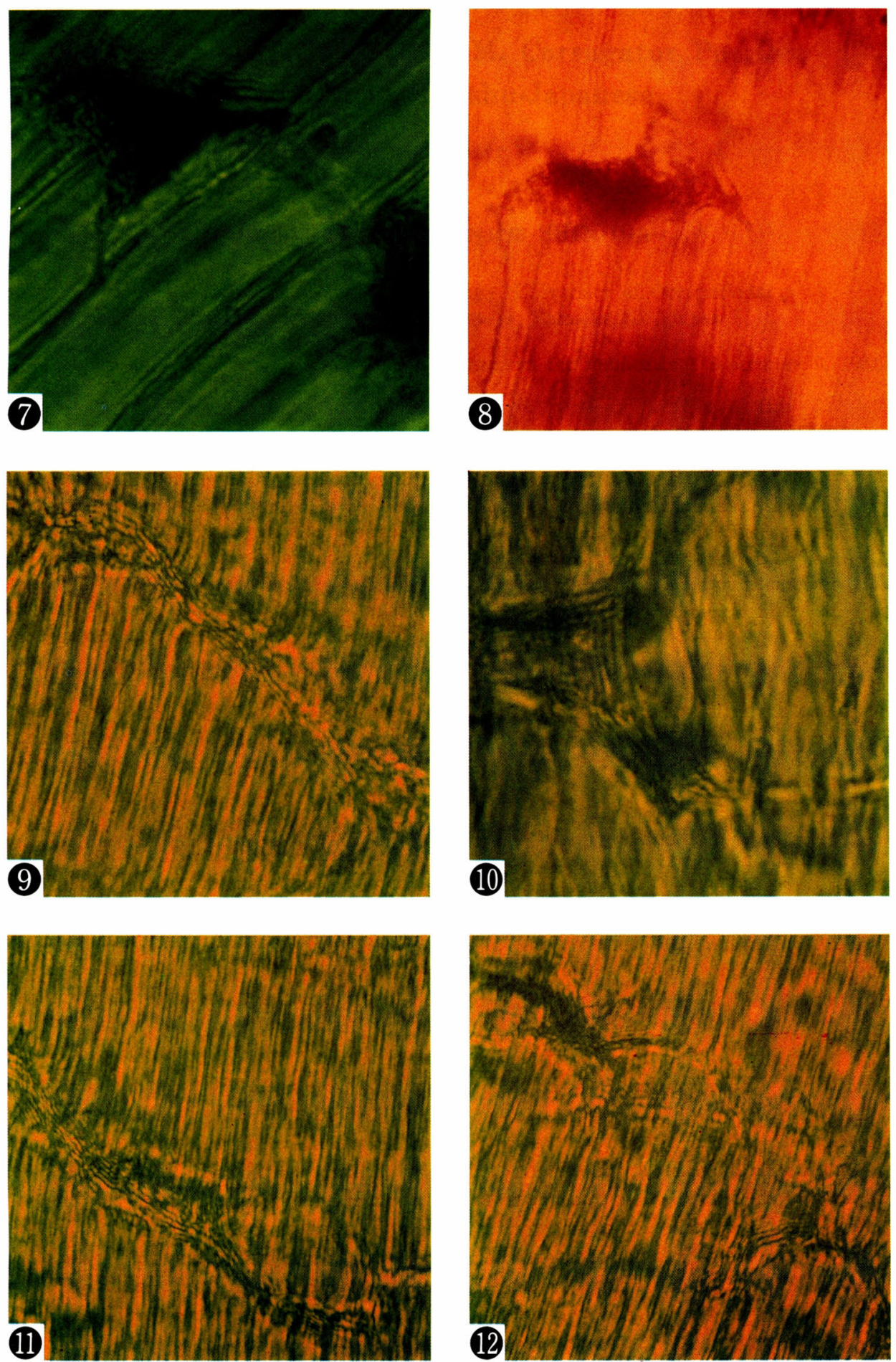

S. Nagahama 